\title{
IMPROVING PROPERTIES OF CAST PARTS OF AGRICULTURAL MACHINERY BY THE NANOMODIFICATION METHOD
}

\author{
Svetlana Kvon, Vitaliy Kulikov, Yelena Chsherbakova, Saniya Arinova \\ Karaganda Technical University, Kazakhstan
}

svetlana.1311@mail.ru,mlpikm@mail.ru,sherbakova_1984@mail.ru,sanya_kazah@mail.ru

\begin{abstract}
The technology of obtaining and treating steel for agricultural machinery consists in smelting steel of the specified composition, modifying the steel with titanium carbide nanopowder in an amount of $0.06-0.08 \%$ with dispersion of 80-100 nm and subsequent heat treatment consisting of the following stages: annealing at $640{ }^{\circ} \mathrm{C}$, quenching in oil at $920-930^{\circ} \mathrm{C}$ and tempering in water at $500-550{ }^{\circ} \mathrm{C}$. As a result of using the developed technology, the properties of parts increase: hardness by $12-14 \%$; tensile strength by $13-15 \%$; wear resistance by $15-18 \%$. The grain class and segregation decrease, the properties of carbon steels approach in hardness and wear resistance to those of heat treated steels with carbide hardening. It has been experimentally proven that the treatment of alloyed steel with titanium carbide nanopowder significantly changes the nature of the interstitial phase (carbides): the average size of carbide inclusions decreases by $36 \%$, the shape factor (the tendency to form a spherical shape) increases by $34 \%$, which favorably affects the properties.
\end{abstract}

Keywords: nanomodifiers, steels, titanium carbide, hardness, wear resistance, carbide inclusions.

\section{Introduction}

A significant amount of agricultural machinery parts is made of low- and medium-alloyed steels, the service life of such parts is very limited, the frequency of changing per season is 3 or more times. Accordingly, the use of materials with higher performance properties will extend the life of these parts.

Studies [1-3] provide data on the positive effect of metal nanoparticles, refractory carbides and oxides on properties, such as wear resistance, hardness, toughness and corrosion resistance. It is shown in [1] that modification of shipbuilding steel with magnesium nanoparticles increases the dispersion of ferrite, which improves the properties of steel as a whole. The results obtained in [2] showed that microalloying with yttrium nanoparticles promotes the formation of a fine structure and improves its properties. In [3], the effect of titanium carbide nanoparticles on the properties of carbon steel was studied. It has been shown that in comparison with cast carbon steel without $\mathrm{TiC}$ nanoparticles, a decrease in grain size and an improvement in mechanical properties are observed.

In previous works $[4 ; 5]$ an experimental steel was investigated, the composition of which is given in Table 1. For comparison, 30H3MF steel was used, as is often used for the manufacture of cast parts. It has been shown that microalloying with vanadium and niobium leads to the formation of carbides of the $\mathrm{MeC}$ type, which have increased resistance and hardness, thereby increasing wear resistance.

Table 1

Chemical composition of the test steel

\begin{tabular}{|l|l|l|l|l|l|l|l|l|l|l|}
\hline Element, \% & $\mathrm{C}$ & $\mathrm{Si}$ & $\mathrm{Mn}$ & $\mathrm{Ni}$ & $\mathrm{S}$ & $\mathrm{P}$ & $\mathrm{Cr}$ & $\mathrm{Mo}$ & $\mathrm{B}$ & $\mathrm{V}+\mathrm{Nb}$ \\
\hline Test steel & 0.32 & 0.6 & 1.7 & 0.55 & 0.025 & 0.025 & 2.3 & 0.28 & - & 0.13 \\
\hline
\end{tabular}

Carbides of the $\mathrm{MeC}$ type, in contrast to the carbides of the cementite type, do not dissolve when heating, remain in the matrix after quenching, thereby providing hardness and strength. In addition, carbides of this type have, as a rule, high dispersion and a more rounded shape, in contrast to acicular carbides of the cementite type. This shape of the carbide phase provides a lower stress level and therefore higher toughness.

The classical heat treatment of steel $30 \mathrm{H} 3 \mathrm{MF}$ is quenching from $870{ }^{\circ} \mathrm{C}$ in oil, followed by tempering at $620^{\circ} \mathrm{C}$ in water [6]. In [4], it was noted that due to additional alloying, the heat treatment mode was corrected: quenching from $890^{\circ} \mathrm{C}$ in oil, followed by tempering in the range of $500-550{ }^{\circ} \mathrm{C}$, cooling in cold water. In connection with the additional modification of the experimental steel, the heat treatment mode was adjusted. The information analysis in this area has shown [7-11] that to increase the structure homogenization, increasing the hardening temperature and preliminary treatment of the structure can improve the final properties of steel.

Pre-annealing of castings made of this steel at the temperature of $640-660^{\circ} \mathrm{C}$ allows homogenizing the structure, eliminating possible casting defects, and reducing the level of chemical segregation. 
Increasing the hardening temperature to $900-930{ }^{\circ} \mathrm{C}$ ensures the dissolution of both cementite and $\mathrm{Me}_{23} \mathrm{C}_{7}$ carbides that form chromium.

In order to study the effect on the structure and properties of the tested steel another NPM was introduced.

\section{Materials and methods}

Titanium carbide in an amount of $0.02-0.1 \%$ by weight and with different dispersion was introduced into the experimental steel. Previously, titanium carbide grade F 500 (TU 6-09-492-75) was ground in a Retsch Emax nanomill with such parameters: grinding balls size $15 \mathrm{~mm}$; rotation frequency $1200 \mathrm{rpm}$. After grinding, the fractional analysis of the obtained titanium carbide powder was carried out on a FSKh-6K photo sedimentometer. Dispersion varied within 60-120 nm with the fraction content of at least $80 \%$.

Experiments on treating experimental steel were carried out according to the developed modes. The pilot steel was melted in a UIP-25 furnace with a modernized cooling system. The melt was poured into alundum crucibles fixed in the ground. Previously, titanium carbide powder was placed in the crucible in specified amounts and dispersion. After complete cooling, the samples were subjected to heat treatment according to the following mode: annealing at the temperature of $650{ }^{\circ} \mathrm{C}$; quenching at the temperature of $920^{\circ} \mathrm{C}$ followed by cooling in oil; tempering at the temperature of $500{ }^{\circ} \mathrm{C}$, cooling in water.

\section{Results and discussion}

After heat treatment according to the indicated conditions the samples were tested for hardness and wear resistance. According to the data of Tables 2 and 3 graphs were built for assessing the optimal ranges of the NPM amount and dispersion (Fig. 1).

TiC dispersion effect on the steel properties (the TiC amount $0.06 \%$ )

\begin{tabular}{|c|c|c|c|}
\hline \multirow{2}{*}{ Sample No. } & Dispersion, & \multicolumn{2}{|c|}{ Properties } \\
\cline { 3 - 4 } & $\mathbf{n m}$ & Hardness, HV & Wear resistance, $\mathbf{x 1 0} \mathbf{4}, \mathbf{g}$ \\
\hline $1 / 1$ & Not introduced & 430 & 322 \\
\hline $1 / 2$ & 60 & 432 & 330 \\
\hline $1 / 3$ & 80 & 452 & 380 \\
\hline $1 / 4$ & 100 & 461 & 416 \\
\hline $1 / 5$ & 120 & 323 & 302 \\
\hline
\end{tabular}

TiC amount effect on the steel properties (dispersion $80 \mathbf{~ n m}$ )

Table 3

\begin{tabular}{|c|c|c|c|}
\hline \multirow{2}{*}{ Sample No. } & \multirow{2}{*}{ TiC amount, $\%$} & \multicolumn{2}{|c|}{ Properties } \\
\cline { 3 - 4 } & & Hardness, HV & Wear resistance, $\mathbf{x 1 0} \mathbf{4}, \mathbf{g}$ \\
\hline $2 / 1$ & Not introduced & 430 & 322 \\
\hline $2 / 2$ & 0.02 & 428 & 320 \\
\hline $2 / 3$ & 0.04 & 445 & 352 \\
\hline $2 / 4$ & 0.06 & 455 & 372 \\
\hline $2 / 5$ & 0.08 & 461 & 416 \\
\hline $2 / 6$ & 0.1 & 512 & 0, chips \\
\hline
\end{tabular}

Analysis of the graphs presented in Figure 1 shows that the most optimal dispersion interval is the particle size range of TiC particles 80-90 $\mathrm{nm}$. With increasing the TiC particle size above $100 \mathrm{~nm}$, the hardness and wear resistance of the samples decreases. This can be explained by the fact that for a given particle size TiC disrupts the homogeneity of the matrix, causing additional stresses around the particle. This phenomenon can be compared with the effect of coagulation of interstitial phases, when upon reaching the critical size, the hardening interstitial phase has an opposite effect rather than the hardening one [8-11]. 
A similar effect is exerted by the introduction of $\mathrm{TiC}$ in the amount greater than $0.08 \%$. With the amount of $\mathrm{TiC}$ in the specified amount, the sample hardness continues growing, but when tested for wear, the surface is chipped. This circumstance is associated with increasing the fraction of solid inclusions incoherent with the matrix, which leads to additional structural tension. Under the impact of dynamic loads, which are all abrasive loads, individual structural components, in this case TiC, crumble.

a)
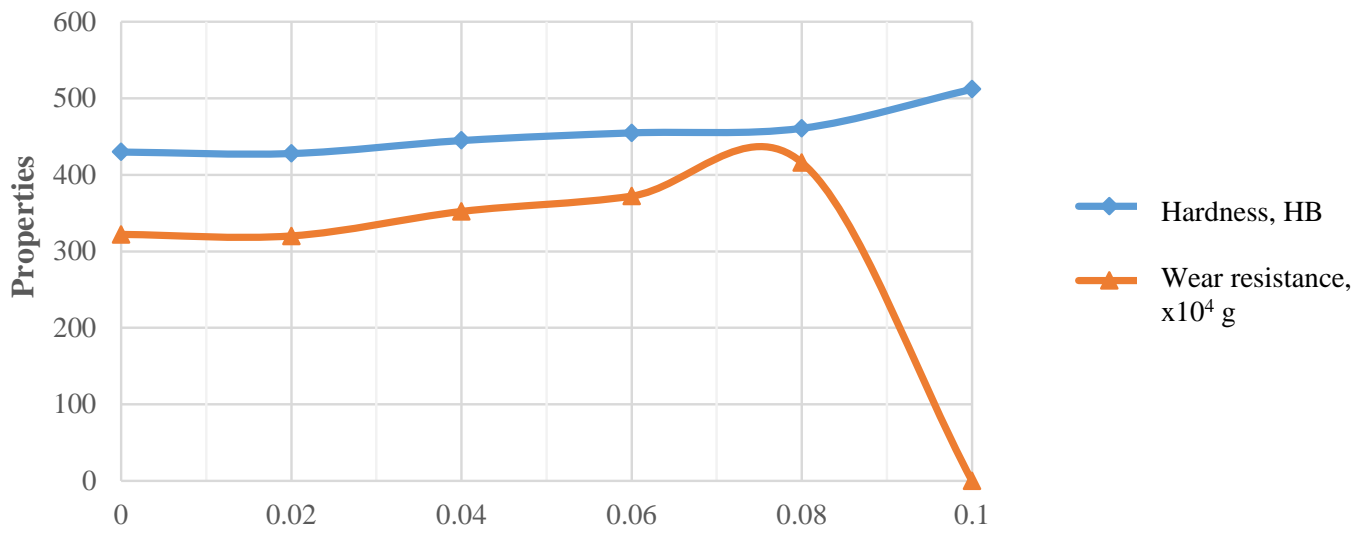

b)

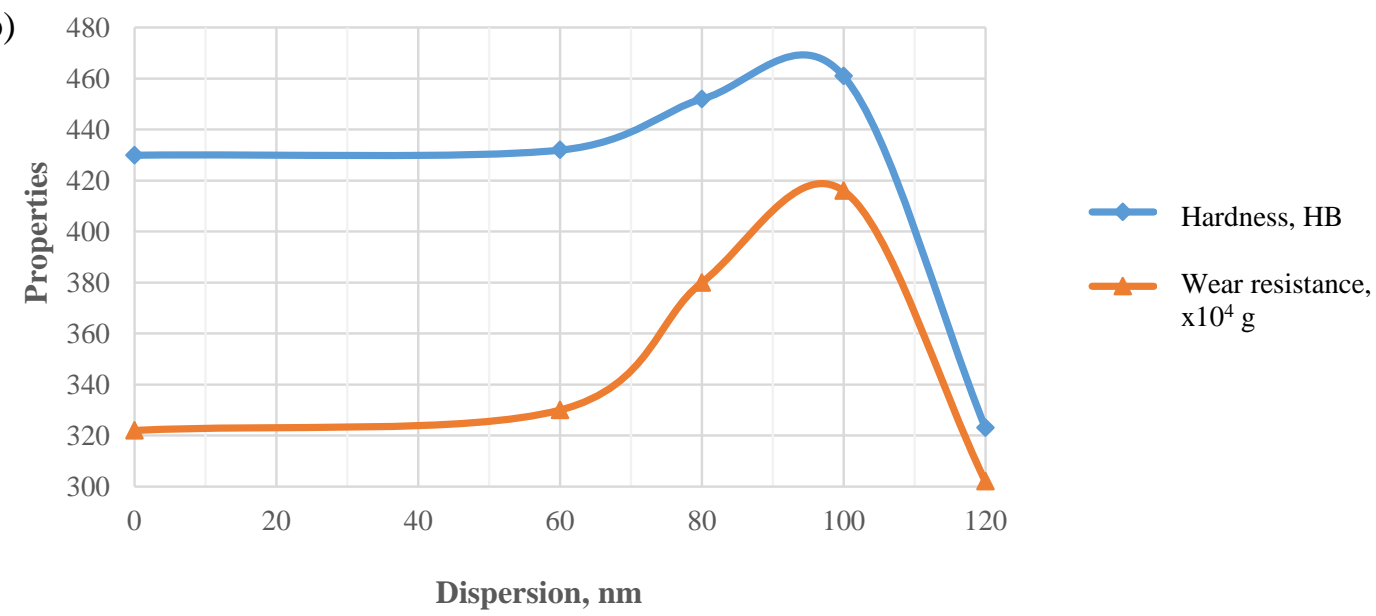

Fig. 1. Dependence of hardness and wear resistance on the amount (a) and dispersion (b) of the introduced $\mathrm{TiC}$

Thus, the tests performed make it possible to recommend the following treatment mode for TiC: the introduction of titanium carbide with dispersion of $80-100 \mathrm{~nm}$ in the amount of $0.06-0.08 \%$. The obtained experimental data show that samples $2 / 4(1 / 3)$ are promising for further research, i.e. the sample modified with titanium carbide with dispersion of $80 \mathrm{~nm}$ in the amount of $0.06 \%$. In this sample, as well as in the reference samples (Table 4), ultimate strength and impact strength were determined.

Table 4

Results of testing for mechanical properties of experimental samples

\begin{tabular}{|c|l|c|c|c|c|}
\hline No & \multicolumn{1}{|c|}{ Sample } & HV & $\begin{array}{c}\text { Ultimate } \\
\text { strength, } \\
\text { MPa }\end{array}$ & $\begin{array}{c}\text { Wear } \\
\text { resistance, } \\
\mathbf{x 1 0}, \mathbf{g}\end{array}$ & $\begin{array}{c}\mathbf{K C U} \\
\mathbf{k J} \cdot \mathbf{m}^{-2}\end{array}$ \\
\hline $1 / 0$ & $\begin{array}{l}\text { Steel 30H3MF } \\
\text { (comparison sample) }\end{array}$ & 326 & 972 & 243 & 912 \\
\hline $1 / 1$ & $\begin{array}{l}\text { Experimental steel } \\
\text { (without, TiC annealing, quenching at } \\
920^{\circ} \mathrm{C} \text { oil + tempering at 500 }{ }^{\circ} \mathrm{C} \text { water }\end{array}$ & 430 & 1317 & 322 & 832 \\
\hline $1 / 3$ & $\begin{array}{l}\text { Experimental steel } \\
\text { (TiC treated, annealing, quenching at } 920 \\
{ }^{\circ} \mathrm{C} \text { oil + tempering at 500 }{ }^{\circ} \mathrm{C} \text { water }\end{array}$ & 452 & 1356 & 380 & 802 \\
\hline
\end{tabular}


It is seen from Table 4 that sample No. 1/3 treated with $\mathrm{TiC}$, in all respects surpasses the reference sample and sample No. 1/2 represented by the same alloy composition, but without subsequent modification with TiC.

In addition to testing prototypes for mechanical properties, metallographic tests were also carried out. Sections were prepared from the steel prototypes for structural analysis. Fig. 2 shows the microstructures and MRSA data of the studied samples. MRSA was performed to determine the nature of the interstitial phases. There are given selected, most typical spectra.

a) steel 6(1)
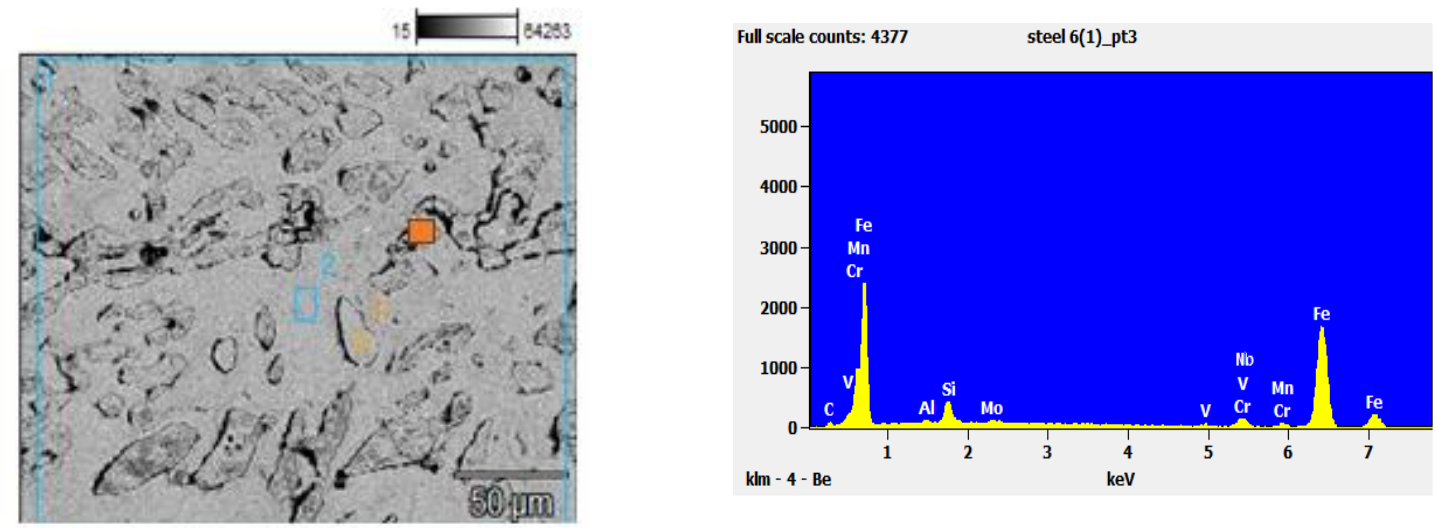

b)
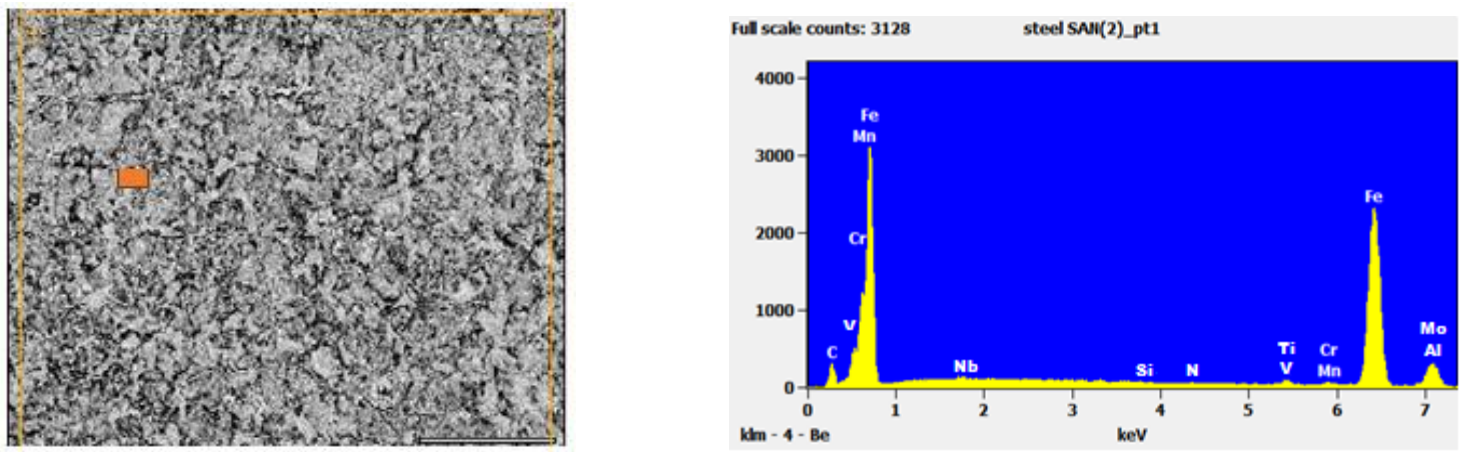

Fig. 2. Structure and composition of the test samples (magnification 5000): a-sample No. 1/2; (the data of 2019); b - sample No. 1/3

The MRSA data show that such elements as $\mathrm{C}, \mathrm{V}, \mathrm{Nb}, \mathrm{Ni}$ are present in the interstitial phases. Taking into account the chemical composition of steel, the phases under study can be identified as carbides.

The quantitative analysis of the microstructure of the prototypes was carried out using the Thixomet Pro software. The program automatically selects the objects according to the specified characteristics and carries out the quantitative analysis according to the required parameters.

The shape factor characterizes the shape of the inclusion, it does not characterize isometry, but the tendency towards the development of a spherical shape of the inclusion. In other words, the higher the values of the shape factor in this case, the closer to the sphere the shape of this inclusion. In this case, inclusions were understood as carbides; the nature of the inclusion was determined by MRSA (Fig. 3).

Fig. 3 and the data of Table 5 show that the microstructure of steel modified with titanium carbide nanopowder is characterized by smaller carbides: this is evidenced by a smaller average diameter and perimeter of the phase under study. With the equal number of objects under study, they occupy a smaller area, both in absolute and in relative terms.

The introduction phases in samples No. $1 / 2$ and No. $1 / 3$ are characterized by a fairly high degree of isometricity: the deviation from 1 is about 0.36 , but in sample No. 1/3 the interstitial phase is characterized by a more spherical shape, judging by the shape factor. Thus, the structure in sample No. $1 / 3$ is characterized by a shallower and more rounded interstitial phase with the same nature of the matrix. Microstructures with the selected interstitial phase are shown in Fig. 3. 
Results of the quantitative metallographic analysis

\begin{tabular}{|c|l|c|c|c|c|c|}
\hline $\begin{array}{c}\text { Sam } \\
\text { ple } \\
\text { No. }\end{array}$ & \multicolumn{1}{|c|}{$\begin{array}{c}\text { Sample } \\
\text { characteristic }\end{array}$} & $\begin{array}{c}\text { Average } \\
\text { value of } \\
\text { the object } \\
\text { area, } \mathbf{m m}^{2}\end{array}$ & $\begin{array}{c}\text { Share of } \\
\text { the } \\
\text { inclusion } \\
\text { area, \% }\end{array}$ & $\begin{array}{c}\text { Average value } \\
\text { of the object } \\
\text { perimeter, } \\
\boldsymbol{\mu m}\end{array}$ & $\begin{array}{c}\text { Average } \\
\text { value of the } \\
\text { diameter, } \\
\boldsymbol{\mu m}\end{array}$ & $\begin{array}{c}\text { Average } \\
\text { value of } \\
\text { the shape } \\
\text { factor }\end{array}$ \\
\hline $1 / 2$ & $\begin{array}{l}\text { Experimental } \\
\text { steel (without } \\
\text { NPM treatment) }\end{array}$ & 9.27 & 2.84 & 14.4 & 4.04 & 0.425 \\
\hline $1 / 3$ & $\begin{array}{l}\text { Experimental } \\
\text { steel (NPM } \\
\text { treated) }\end{array}$ & 4.42 & 1.17 & 8.58 & 2.61 & 0.64 \\
\hline
\end{tabular}

The presence of such a structure should provide high strength properties with good impact strength. Microstructures characterized by finer and more rounded interstitial phases (Fig. 3) are characterized by higher hardness and wear resistance. The exceptions are objects 13, 14, which have significant deviations from the average. These objects are characterized by their large size, low isometricity and shape factor. Obviously, in the absence of these objects, the average values of the $1 / 3$ sample would be even higher. The comparison of microstructures shows that despite the large total area of solid interstitial phases $(2.84 \%$ and $1.17 \%)$, the sample $1 / 2$ hardness is lower than that of the specimen $1 / 3$. This contradiction can be easily explained, if we pay attention to the shape of the inclusions. In sample No. $1 / 2$, the carbide phase has an elongated shape (the degree of sphericity is 0.425 ). This phase acts as a stress concentrator, which determines relatively low hardness and wear resistance.

a)

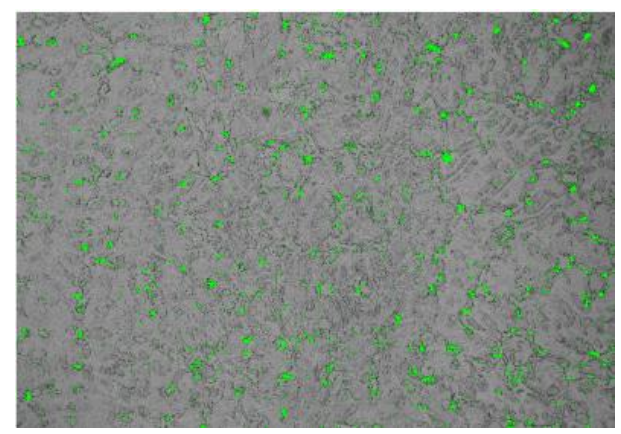

b)

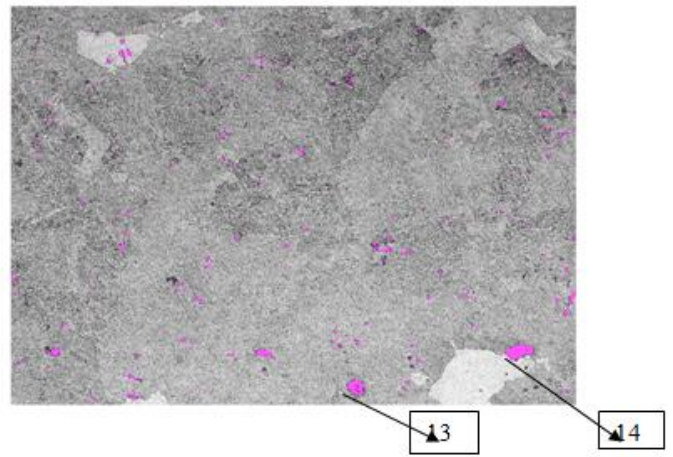

Fig. 3. Microstructure of samples with the pointed omterstitital phase: a - sample $1 / 2 ; b$ - sample $1 / 3$

In the structure of sample No. $1 / 3$, the proportion of the carbide phase over the area is almost 2 times smaller, but the degree of sphericity is 0.64 . It should be noted that the shape of the resulting carbide phase indirectly confirms the nature of the carbide phase. It is known that carbides of the cementite type usually crystallize into an elongated shape and carbides of the $\mathrm{MeC}$ type into a round shape [12-15].

\section{Conclusions}

The results obtained show that steel $30 \mathrm{H} 3 \mathrm{MF}$ additionally alloyed with vanadium and niobium in the amount of $0.15-0.2 \%$ and modified with TiC nanopowder in an amount of $0.06-0.08 \%$ with dispersion of 80-100 nm and subjected to heat treatment that consists of annealing at $640{ }^{\circ} \mathrm{C}$, quenching in oil $920^{\circ} \mathrm{C}$ and tempering in water $500{ }^{\circ} \mathrm{C}$ can be used as a material with good hardness and wear resistance.

Thus, based on the results of studying the properties of the laboratory samples, the following process adjustment can be proposed. The technology was proposed for producing steel based on 30H3MF with an increased content of vanadium and niobium and the further step, which consists in TiC treating of experimental steel and subsequent heat treatment. The modes of TiC treatment and heat treatment are indicated above. 


\section{References}

[1] Zou X., Sun J., Matsuura H. In situ observation of the nucleation and growth of ferrite laths in the heat-affected zone of eh36-Mg shipbuilding steel subjected to different heat inputs. Metall. Mater. Trans. B Process Metall. Mater. Process. Sci. 2018, 49, pp. 2168-2173.

[2] Yu Y.-c., Li H., Wang S.-b. Effect of yttrium on the microstructures and inclusions of EH36 shipbuilding steel. Metall. Res. Technol. 2017, 114 p.

[3] Park J., Hong S., Park E.K., Kim K., Lee M., Rhee C. Microstructure and properties of SA 106B carbon steel after treatment of the melt with nano-sized TiC particles//Materials Science, 2014, DOI: 10.1016/j.msea.2014.06.103.

[4] Issagulov A.Z., Ibatov M.K., Kvon Sv.S., Kulikov V.Yu., Arinova S.K. Studying of properties and microstructureof $30 \mathrm{CrMoV} 9$ steel on wear resistance. Metalurgija, Хорватия, 2019, No. 58 (34), pp. 326-328.

[5] Issagulov A.Z., Ibatov M.K., Kvon Sv.S., Kulikov V.Yu., Ryaboschuk S., Kovalev P.V.// Improving shipbuilding steel grade quality at stages of smelting, secondary refining, and continuous casting// Metals, Switzerland, 2019, No. 9 (2), 203 p.

[6] Dub A.V., Barulenkova N.V., Morozova T.V., Yefimov S.V., Filatov V.N., Zinchenko S.D., Lamukhin A.M. Nemetallicheskiye vklyucheniya vnizkolegirovannoy trubnoy stali. MetallurgMetallurgist, 4, 2004, pp. 67-73. (In Russian)

[7] Smallman R.E., Ngan A.H. Modern Physical Metallurgy, 2014 pp.473-498.

[8] Clarke K.D. Thermal Engineering of Steel Alloy SystemsComprehensive Material process, 2014.

[9] Sankaran K.K., Mishra R.S. Ultra Strengh Steels, Metallurgy and Design of Alloys with Hierarchical Microstucture, 2017.

[10] Rose A., Hougardy H. Transformation Characteristics and Hardenability of Carburizing Steels. In Transformation and Hardenability in Steels; Climax Molybdenum Company of Michigan, 1967; pp. $155-167$.

[11] Silva A.C. Non-metallic inclusions in steels - origin and control. Journal of Materials Research and Technology, 2018, 7(3).

[12] Pastukhov A., Sharaya O.A., Vodolazskaya N.,Minasyan A. Hardening of parts of agricultural machinery with laser micro alloying. Engineering for rural development. Proceedings, Vol 17, Latvia University of Life Sciences and Technologies, 2018, pp. 1360-1365.

[13] Pastukhov A., Timashov E., Sharaya O., Bakharev D. CAE-justification of the leading shaft of the test stand 7 th TAE. Prague, Czech Republic. - 2019, pp. 429-434.

[14] Kvon S.S., Kulikov V.Y., Shcherbakova Y.P., Arinova S.K. Effect of inoculant introducing on improving ingot structure. Metalurgija, 2019, 58(3-4), pp. 315-318.

[15] Kvon S.S., Kulikov V.Y., Issagulov A. Z., Dostayeva A. M., Kovalyova T.V. Studying structure and properties of shaped ingots obtained in various conditions of crystallization. Metalurgija 2018, 57(4), pp. 313-316. 